\title{
Development and psychometric evaluation of the Mandarin Chinese version of the Yale-Brown Obsessive-Compulsive Scale - Second Edition
}

\author{
Chen C. Zhang, ${ }^{1}$ Hengfen Gong, ${ }^{2}$ Yingying Zhang, ${ }^{1}$ Haiyan Jin, ${ }^{3}$ Yong Yang, ${ }^{4}$ Bin $\mathbf{L i},{ }^{5}$ Yongchao \\ $\mathbf{L i}^{5}{ }^{5}$ Xiao Luo, ${ }^{6}$ Wenjuan Liu, ${ }^{7}$ Fang Fang, ${ }^{8}$ Bin Li ${ }^{9}$ Bomin Sun, ${ }^{1}$ Terri Fletcher, ${ }^{10}$ Valerie La \\ Buissonnière-Ariza, ${ }^{10}$ Wayne K. Goodman, ${ }^{10}$ Eric A. Storch ${ }^{10}$ iD
}

\begin{abstract}
${ }^{1}$ Department of Functional Neurosurgery, Ruijin Hospital, Shanghai Jiao Tong University School of Medicine, Shanghai, China. ${ }^{2}$ Department of Psychiatry, Pudong District Mental Health Center, Shanghai, China. ${ }^{3}$ Department of Psychiatry, Ruijin Hospital, Shanghai Jiao Tong University School of Medicine, Shanghai, China. ${ }^{4}$ Department of Psychiatry, Suzhou Guangji Hospital, Suzhou, Jiangsu, China. ${ }^{5}$ Department of Psychiatry, Yangpu District Mental Health Center, Shanghai, China. ${ }^{6}$ Department of Psychiatry, The First Affiliated Hospital of Xinjiang Medical University, Xinjiang, China. ${ }^{7}$ Department of Psychological Medicine, Zhongshan Hospital, Fudan University, Shanghai, China. ${ }^{8}$ Department of Psychotherapy, Shanghai Hongkou Mental Health Center, Shanghai, China. ${ }^{9}$ Department of Psychiatry, West China Hospital, Sichuan University, Chengdu, Sichuan, China. ${ }^{10}$ Menninger Department of Psychiatry and Behavioral Sciences, Baylor College of Medicine, Houston, TX, USA.
\end{abstract}

\begin{abstract}
Objective: To examine the psychometric properties of the Chinese version of the Yale-Brown Obsessive Compulsive Scale - Second Edition (Y-BOCS-II).

Method: A total of 86 adults with a primary diagnosis of obsessive-compulsive disorder (OCD), ranging in age from 15 to 78 years, participated in the study. Participants were administered the Y-BOCS-II by a trained clinician who also rated overall illness severity on two additional measures. Patients completed the Obsessive Compulsive Inventory-Revised and Depression Anxiety Stress Scale-21.

Results: Results indicated high internal consistency and fair 1-week test retest reliability. The Y-BOCS-II scales correlated strongly with clinician-rated obsessive-compulsive severity and modestly with self-reported obsessive-compulsive symptom frequency and distress. The relationship between Y-BOCS-II total score and depressive and anxiety symptoms was strong, which may reflect high rates of comorbid conditions in this sample or the linkage between obsessive-compulsive symptom severity and distress. Factor analysis demonstrated a two-factor structure consisting of obsession and compulsion factors, with interference due to obsessions cross-loading.

Conclusions: Overall, these results support the use of the Y-BOCS-II among individuals from China. Future study by an independent group is necessary to replicate these findings, as well as investigate interrater reliability and treatment sensitivity.
\end{abstract}

Keywords: Obsessive-compulsive disorder; assessment; reliability; treatment

\section{Introduction}

Obsessive-compulsive disorder (OCD) is a potentially debilitating psychiatric condition affecting approximately $1-2 \%$ of individuals worldwide. ${ }^{1}$ Core features include the presence of obsessions (i.e., unwanted, intrusive thoughts, or images that cause distress) and/or compulsions (i.e., overt/covert acts intended to reduce obsessional distress). ${ }^{2}$ Although OCD is associated with considerable psychiatric morbidity ${ }^{3}$ and reduced quality of life, ${ }^{4,5}$ there are effective interventions for its management, including cognitive-behavioral therapy with exposure and response prevention and antidepressant pharmacotherapy. ${ }^{6,7}$

Correspondence: Eric A. Storch, Baylor College of Medicine, Menninger Department of Psychiatry and Behavioral Sciences, 1977 Butler Blvd, Suite 4-400, 77030, Houston, TX, USA.

E-mail: eric.storch@bcm.edu

Submitted Apr 12 2018, accepted Oct 15 2018, Epub Feb 182019.
Receipt of and monitoring during treatment require clear assessment of symptom presence and severity. Although a number of measures have been introduced in this regard (see Benito \& Storch ${ }^{8}$ for reviews), the YaleBrown Obsessive-Compulsive Scale ${ }^{9,10}$ (Y-BOCS) has historically been considered the gold-standard method for clinician rating of obsessive-compulsive symptom presence and severity. However, several overarching concerns about the original Y-BOCS have been raised. First, the Y-BOCS did not effectively delineate rating avoidance within the severity items, despite the core feature of this phenomenon. ${ }^{11,12}$ Second, the Y-BOCS scoring range of 0 to 40 has limited utility for assessment the most
How to cite this article: Zhang $\mathrm{CC}$, Gong $\mathrm{H}$, Zhang $\mathrm{Y}$, Jin $\mathrm{H}$, Yang Y, Li B, et al. Development and psychometric evaluation of the Mandarin Chinese version of the Yale-Brown Obsessive-Compulsive Scale - Second Edition. Braz J Psychiatry. 2019;41:494-498. http:// dx.doi.org/10.1590/1516-4446-2018-0126 
severely affected patients, due to insufficient differentiation between individuals who present at the upper limits of severity and those experiencing severity that is beyond the Y-BOCS ceiling. Indeed, past studies found that patients were regularly rated using the extreme scores. ${ }^{1}$ Third, the resistance to obsessions item has demonstrated poor psychometric properties ${ }^{13-15}$ and is conceptually inconsistent with the tenets of cognitive-behavioral therapy, which advise against resisting or suppressing obsessions. Finally, the Y-BOCS symptom checklist required updates to account for avoidance, clarify item content by providing additional examples of potential symptoms, and remove predefined dimensional headings, since symptoms often cross dimensional categories (e.g., checking rituals related to contamination or sexual obsessions). In response to these concerns, the YaleBrown Obsessive-Compulsive Scale - Second Edition ${ }^{16}$ (Y-BOCS-II) was created.

To date, several investigations have been conducted on the psychometric properties of the Y-BOCS-II. Findings have supported its psychometric properties, including strong internal consistency (alpha $=0.75-0.91$ ), test-retest reliability (intraclass correlation coefficient $[\mathrm{ICC}]=0.96$ ), and interrater reliability $\left(\mathrm{ICC}=0.97-0.99^{16,17}\right)$. Construct validity has been supported vis-à-vis correlations with measures of obsessive-compulsive severity and frequency. ${ }^{17}$ Divergent validity has been supported through weak to moderate relations with anxiety and depressive symptoms. ${ }^{17}$

To date, the Y-BOCS-II has been translated into two other languages: Thai and Italian. ${ }^{18,19}$ No attempts have been made to translate it into Chinese, a language family spoken by over 1 billion individuals, of whom $2-3 \%$ present with a lifetime diagnosis of OCD. ${ }^{20}$ The purpose of this study was to translate the Y-BOCS-II into Mandarin Chinese and evaluate its psychometric properties among individuals affected by OCD. Our specific questions examined the following: first, what is the internal consistency and 1-week test-retest reliability of the Y-BOCS-II? Second, to what extent does the Y-BOCS-II severity scale correlate with measures of obsessive-compulsive severity, as well as depression and anxiety symptoms? Third, what is the factor structure of the Y-BOCS-II?

\section{Methods}

\section{Participants}

Participants were recruited from the regular patient flow at several outpatient psychiatry clinics during one of their regularly scheduled appointments. To be eligible for participation in the study, participants had to have a diagnosis of OCD confirmed by a licensed psychologist or psychiatrist through a clinical interview, be between the ages of 15 and 70 years, and be speakers of Mandarin Chinese. The clinical interview conformed to the DSM-5 and consisted of approximately 1 hour of unstructured clinical discussion of symptomology and associated impairment. Exclusion criteria included diagnosis of psychotic disorder and inability to read and understand assessment measures.

\section{Procedures}

Informed consent was obtained from participants prior to participation, as approved by the institutional review board. In the case of minors, parental consent and child assent were obtained. There were no differences across measures between minors and adults. All study measures were completed during or after participants' scheduled appointments. Initial assessment included administration of the Mandarin Chinese version of the Y-BOCS-II and other clinician-rated measures by trained masters'- or doctoral-level clinicians and completion of self-report measures. For 25 participants $(29.1 \%$ of the sample), a follow-up session was scheduled 1 week after initial assessment for re-administration of the Y-BOCS-II to examine test-retest reliability.

\section{Measures}

\section{Clinician-administered measures}

1) Yale-Brown Obsessive Compulsive Scale - Second Edition, Mandarin Chinese version (Y-BOCS-II). The Y-BOCS-II ${ }^{16}$ is the revised version of the Yale-Brown Obsessive Compulsive Scale ${ }^{10}$ (Y-BOCS). It is a semistructured interview comprising a Symptom Checklist and a Severity scale. The Symptom Checklist includes a list of 67 possible obsessions, compulsions, and avoidance behaviors experienced over the past 30 days. The Severity scale is a 10-item measure of obsession and compulsion severity. Items are rated on a six-point scale ranging from 0 to 5 referring to the week preceding the interview, with higher scores corresponding to greater severity. All items are summed to derive the Total Severity Score. The English version of the Y-BOCS-II has demonstrated excellent psychometric properties, including high internal consistency (0.84-0.89), test-retest $(0.85)$ and interrater reliability $(0.96)$, and good construct validity. ${ }^{16}$

2) Clinical Global Impression - Severity ${ }^{21}$ (CGI-S). The CGI-S is a one-item, clinician-rated measure designed to assess the severity of psychopathology on a seven-point scale. Severity ratings range from 0 to 6 , with 0 indicating no illness and 6 indicating extremely severe symptoms (i.e., respondent is completely nonfunctional). The CGI-S has been widely used and has demonstrated adequate sensitivity to treatment in a large array of clinical research studies for numerous disorders, including OCD. ${ }^{22-24}$

3) National Institute of Mental Health Global Obsessive Compulsive Scale ${ }^{25}$ (NIMH-GOCS). The NIMH-GOCS is a one-item, clinician-rated measure of OCD symptom severity and global functioning. The item is rated on a 15-point scale ranging from 1 (minimal symptoms) to 15 (very severe symptoms). The NIMH-GOCS has good interrater reliability $\left(r_{s}=0.77-0.95\right)$, high testretest reliability $\left(r_{\mathrm{s}}=0.87-098\right)$, and has been shown to be change-sensitive and to correlate strongly with the Y-BOCS (for a review, see Grabill et al. ${ }^{26}$ ).

\section{Self-report measures}

1) Obsessive-Compulsive Inventory - Revised ${ }^{27}$ (OCl-R). The OCl-R is an 18-item self-report measure designed to 
assess the presence of and distress associated with specific obsessive-compulsive symptoms across six subscales: washing, obsessing, hoarding, ordering, checking, and neutralizing. Items are rated on a five-point Likert scale ranging from 0 (not at all) to 4 (extremely), with higher scores reflecting higher obsessive-compulsive symptom severity. Scores can be computed separately for the six subscales or through a total score by summing the items. The OCl-R has demonstrated high internal consistency (0.83), high 2-week test-retest reliability $\left(r_{\mathrm{s}}=0.74-0.91\right)$, as well as good diagnostic ability and construct, convergent, and discriminant validity. ${ }^{26-29}$

2) Depression Anxiety Stress Scales - 21-Item Version $^{30}$ (DASS-21). The DASS-21 is, as its name implies, a 21-item self-report measure assessing the presence and severity of anxiety (DASS-A), stress (DASS-S), and depressive (DASS-D) symptoms. Each subscale contains seven items rated on a four-point Likert scale ranging from 0 (does not apply to me at all) to 3 (applies to me very much, or most of the time). For each subscale, scores are summed and then doubled for consistency with the 42-item version of the DASS. Participants are considered to have elevated symptom levels if they score in the severe or extremely severe range (DASS-D $\geqslant 21$, DASS-A $\geqslant 15$, DASS-S $\geqslant 26^{30}$ ). The DASS-21 has demonstrated good internal consistency (alpha $=0.87$ for DASS-A, 0.91 for DASS-S, and 0.94 for DASS-D) and validity.

\section{Data analyses}

We first analyzed any differences in scores between adolescents and adults; no significant differences between groups were found, nor in the overall pattern of findings (with or without adolescents). Thus, we retained the full sample for the subsequent analyses. Cronbach's alpha coefficient was used to evaluate the internal consistency of the Y-BOCS-II Severity Scale and the Obsession and Compulsion Severity subscales. The Kuder-Richardson Formula 20 was used to assess internal consistency of the Y-BOCS-II Symptom Checklist. Construct validity of the Y-BOCS-II Severity Scale and the Obsession and Compulsion Severity subscales was assessed using bivariate correlations. The ICC was used to examine test-retest reliability. All analyses assessing internal consistency, construct validity, and test-retest reliability were conducted in IBM SPSS version 24.

A confirmatory factor analysis (CFA) was conducted to evaluate the applicability of the obsessions and compulsions two-factor solution as well as the proposed interference/severity and resistance/control two-factor solution. ${ }^{13,15,31}$ To assess goodness of fit, the comparative fit index ${ }^{32}(\mathrm{CFI})$ and the root-mean-square error of approximation $^{33}$ (RMSEA) were examined. CFI values greater than 0.90 reflect good model fit; RMSEA values below 0.05 indicate close fit, values around 0.08 indicate adequate fit, and values above 0.10 indicate poor fit. ${ }^{33}$ Chi-square is also reported, with significant values indicating poor fit; however, it is considered a more useful means of comparing nested models than an absolute

\section{Table 1 Descriptive measures}

\begin{tabular}{lcc}
\hline Measure & Mean (SD) & Range \\
\hline $\begin{array}{l}\text { Yale-Brown Obsessive-Compulsive } \\
\text { Scale - Second Edition, Mandarin }\end{array}$ & \\
Chinese version & & \\
$\quad$ Severity & $26.00(9.12)$ & $7-44$ \\
$\quad$ Obsessions & $13.16(4.80)$ & $4-23$ \\
$\quad$ Compulsions & $12.84(5.46)$ & $0-23$ \\
& & \\
Clinical Global Impressions - Severity & $4.51(1.23)$ & $0-7$ \\
National Institute of Mental Health - & $8.10(2.56)$ & $2-13$ \\
$\quad$ Global Obsessive-Compulsive Severity & & \\
Obsessive-Compulsive Inventory - & $21.36(14.18)$ & $0-51$ \\
$\quad$ Revised & & \\
& & \\
Depression, Anxiety and Stress & & \\
$\quad$ Scale - 21 & & \\
$\quad$ Depression & $14.64(11.80)$ & $0-42$ \\
$\quad$ Anxiety & $12.75(10.24)$ & $0-42$ \\
$\quad$ Stress & $12.75(11.99)$ & $0-42$ \\
\hline
\end{tabular}

indicator of model fit. ${ }^{34}$ Subsequent exploratory factor analysis was conducted with principal-axis factoring and a geomin oblique rotation. Factor selection was determined on the basis of eigenvalues ( $>1.00$ ), examination of the scree plot deflection, and interpretability. All factor analyses were conducted in Mplus version 5.21 (Muthén \& Muthén, Los Angeles, USA).

\section{Results}

The sample $(n=86)$ was $51 \%$ male and $96 \%$ of Han nationality. Participants ranged in age from 15 to 78 years $($ mean $=35.4$, standard deviation $[S D]=14.5)$ and reported an average of 13.2 years of education (SD = 3.5). The average age of OCD onset was 24.5 (SD = 12.6) and the duration of OCD symptoms ranged from 1 to 44 years $($ mean $=11.9, \mathrm{SD}=8.8)$. Descriptive statistics of the Y-BOCS-II and other study measures are presented in Table 1.

\section{Reliability and validity}

The Y-BOCS-II demonstrated high internal consistency (alpha $=0.90$ ), as did the obsessions and compulsions subscales (alpha $=0.87$ and 0.88 , respectively). The internal consistency of the Y-BOCS-II Symptom Checklist was also high (alpha $=0.88$ ). The test-retest reliability of the Y-BOCS-II was calculated in a subset of the sample $(n=25)$ who completed a second rating 1 week after the initial evaluation, and was found adequate $(I C C=0.63)$.

Convergent validity of the Y-BOCS-II Severity Scale with the CGI-S and NIMH-GOCS was strong $(r=0.75$ and 0.71 ). The Y-BOCS-II Severity Scale also correlated significantly positively with the OCl-R $(r=0.39)$ and with the DASS Depression $(r=0.49)$, Anxiety $(r=0.46)$, and Stress Scales $(r=0.52)$. The Y-BOCS-II Obsessions and Compulsions Severity subscales were also significantly positively correlated with measures of OCD severity and with the DASS. 
Table 2 Exploratory factor analysis item loadings

\begin{tabular}{lcc}
\hline Y-BOCS-II item & $\begin{array}{c}\text { Factor 1- } \\
\text { Obsessions }\end{array}$ & $\begin{array}{c}\text { Factor 2- } \\
\text { Compulsions }\end{array}$ \\
\hline 1. Time on obsessions & $\mathbf{0 . 9 0}$ & -0.67 \\
2. Obsession-free interval & $\mathbf{0 . 8 4}$ & -0.00 \\
3. Control over obsessions & $\mathbf{0 . 5 7}$ & -0.25 \\
4. Distress associated with & $\mathbf{0 . 7 7}$ & 0.15 \\
obsessions & & \\
5. Interference from obsessions & $\mathbf{0 . 4 4}$ & $\mathbf{0 . 4 1}$ \\
6. Time on compulsions & 0.35 & $\mathbf{0 . 4 3}$ \\
7. Resistance to compulsions & 0.01 & $\mathbf{0 . 7 9}$ \\
8. Control over compulsions & -0.06 & $\mathbf{0 . 9 4}$ \\
9. Distress if compulsions prevented & 0.00 & $\mathbf{0 . 8 2}$ \\
10. Interference from compulsions & 0.21 & $\mathbf{0 . 6 9}$
\end{tabular}

Bold font indicates the factor(s) on which the item primarily loaded. Y-BOCS-II = Yale-Brown Obsessive-Compulsive Scale - Second Edition, Mandarin Chinese version.

\section{Factor structure}

We conducted two separate CFAs to test the two-factor solutions represented by the obsessions and compulsions factors (model 1) and the interference/severity and resistance/control factors (model 2). Model 1 specified that items 1-5 would load on the obsessions factor and items 6-10 would load on the compulsions factor, whereas model 2 specified that items 1, 2, 3, 6, 7, and 8 would load on the interference/severity factor and items 4, 5, 9, and 10 would load on the resistance/control factor. The CFA for model 1 revealed that the original obsessions and compulsions two-factor structure was a poor fit to the data, with $\chi^{2}(34, \mathrm{n}=86)=134.95, \mathrm{p}<0.0001, \mathrm{CFI}=0.83$, and RMSEA $=0.19$. Similarly, the CFA for model 2 revealed the interference/severity and resistance/control two-factor structure was also a poor fit to the data, with $\chi^{2}(34, \mathrm{n}=86)=231.63, \mathrm{p}<0.0001, \mathrm{CFI}=0.66$, and RMSEA $=0.26$. These results suggest that neither of the original two-factor structures are appropriate for this sample of patients, and that further exploration of the dimensionality of the Y-BOCS-II is warranted.

We next conducted an exploratory factor analysis using the geomin oblique factor rotation method. Examination of the scree plot suggested a two-factor solution with eigenvalues of 5.40 and 1.65. Factor loadings for all items are presented in Table 2. Consistent with the results of Storch et al., ${ }^{16}$ Y-BOCS-II items loaded to the obsessions and compulsions factors as expected, with the exception of item 5 (interference due to obsessive thoughts), which loaded to both the obsessions and compulsions factors.

\section{Discussion}

We report on the psychometric properties of the Y-BOCS-II in a Chinese sample of patients with OCD. Overall reliability was excellent in terms of internal consistency and shortterm test-retest reliability; both were consistent with prior investigations. ${ }^{16,17}$ Interrater reliability was not assessed due to practical constraints (i.e., availability of a second clinician, ability to record interviews in clinic settings); we highlight this for future examination.
Construct validity was supported through several methods. The Y-BOCS-II severity scale correlated strongly with other clinician ratings of OCD severity. There was a moderate correlation between the Y-BOCS-II severity scale and self-reported obsessive-compulsive symptom frequency and distress. This association, however, was not as robust as that for depressive and general anxiety symptoms. This is not altogether discrepant from other studies on the $\mathrm{Y}$-BOCS- $-\mathrm{II}^{17}$ and $\mathrm{Y}$-BOCS, ${ }^{13}$ and may speak to high rates of comorbidity in patients with $O C D,{ }^{35}$ such that greater OCD symptomatology is associated with greater overall psychopathology. It is also possible that the Y-BOCS-II measures a slightly different construct than the $\mathrm{OCl}-\mathrm{R}$, with the latter focusing more on symptom frequency and associated distress across six factors, whereas the former is based on overall obsessivecompulsive symptom severity.

Consistent with Storch et al., ${ }^{16}$ Y-BOCS-II items loaded to the obsessions and compulsions factors, except for item 5, interference due to obsessive thoughts, which loaded to both the obsessions and compulsions factors. This may suggest a general interference domain that is dually affected by obsessions and compulsions and/or challenges with distinguishing interference specific to obsessions vs. compulsions. Other items may be differentiated more clearly by patients and clinicians, resulting in relatively independent factor loadings. Overall, this factor model generally makes sense in articulating obsession and compulsion severity as separate but linked clinical phenomena.

Despite the strengths of this study, several limitations must be noted. First, interrater reliability was not assessed. Second, longer test-retest intervals are needed. Third, the sensitivity of the Y-BOCS-II to treatment was not examined. Finally, although well-trained psychiatrists evaluated the status of OCD as a clinically relevant diagnosis (i.e., a significant cause of impairment and/or distress), we did not systematically collect data on comorbid conditions. Within these limitations, this is the first report of the Y-BOCS-II in a sample of individuals with OCD from China. Although replication is needed by an independent research group, these results suggest that the Chinese version of the Y-BOCS-II is a reliable and valid measure of obsessive compulsive symptom severity. We highlight several other areas for future work, including 1) examining how the Y-BOCS-II converges with other self-reported OCD measures beyond those used in this study; 2) treatment sensitivity; and 3) interrater reliability.

\section{Acknowledgements}

We acknowledge the contributions of Sandra Cepeda, Sophie Schneider, and Kristina Zeljic. The final authors (WKG, EAS) retain copyright of the Y-BOCS-II.

\section{Disclosure}

The authors report no conflicts of interest. 


\section{References}

1 Sasson Y, Zohar J, Chopra M, Lustig M, lancu I, Hendler T. Epidemiology of obsessive-compulsive disorder: a world view. J Clin Psychiatry. 1997;58:7-10.

2 American Psychiatric Association. Diagnostic and Statistical Manual of Mental Disorders, Fifth Edition (DSM-5). Arlington: American Psychiatric Publishing; 2013.

3 Pinto A, Mancebo MC, Eisen JL, Pagano ME, Rasmussen SA. The Brown longitudinal obsessive compulsive study: clinical features and symptoms of the sample at intake. J Clin Psychiatry. 2006;67: 703-11.

4 Grabe HJ, Meyer C, Hapke U, Rumpf HJ, Freyberger HJ, Dilling H, et al. Prevalence, quality of life and psychosocial function in obsessivecompulsive disorder and subclinical obsessive-compulsive disorder in northern Germany. Eur Arch Psychiatry Clin Neurosci. 2000;250:262-8.

5 Kugler BB, Lewin AB, Phares V, Geffken GR, Murphy TK, Storch EA Quality of life in obsessive-compulsive disorder: the role of mediating variables. Psychiatry Res. 2013;206:43-9.

6 Skapinakis P, Caldwell DM, Hollingworth W, Bryden P, Fineberg NA Salkovskis $\mathrm{P}$, et al. Pharmacological and psychotherapeutic interventions for management of obsessive-compulsive disorder in adults: a systematic review and network meta-analysis. Lancet Psychiatry. 2016;3:730-9.

7 McGuire JF, Piacentini J, Lewin AB, Brennan EA, Murphy TK, Storch EA. A meta-analysis of cognitive behavior therapy and medication for child obsessive-compulsive disorder: moderators of treatment efficacy, response, and remission. Depress Anxiety. 2015;32:580-93.

8 Benito K, Storch EA. Assessment of obsessive-compulsive disorder: review and future directions. Expert Rev Neurother. 2011;11:287-98.

9 Goodman WK, Price LH, Rasmussen SA, Mazure C, Fleischmann RL, Hill CL, et al. The Yale-Brown Obsessive Compulsive Scale. I. Development, use, and reliability. Arch Gen Psychiatry. 1989;46:1006-11.

10 Goodman WK, Price LH, Rasmussen SA, Mazure C, Delgado P, Heninger GR, et al. The Yale-Brown Obsessive Compulsive Scale. II. Validity. Arch Gen Psychiatry. 1989;46:1012-6.

11 Lewin AB, Caporino N, Murphy TK, Geffken GR, Storch EA. Understudied clinical dimensions in pediatric obsessive compulsive disorder. Child Psychiatry Hum Dev. 2010;41:675-91.

12 McGuire JF, Storch EA, Lewin AB, Price LH, Rasmussen SA, Goodman WK. The role of avoidance in the phenomenology of obsessive-compulsive disorder. Compr Psychiatry. 2012;53:187-94.

13 Deacon BJ, Abramowitz JS. The Yale-Brown Obsessive Compulsive Scale: factor analysis, construct validity, and suggestions for refinement. J Anxiety Disord. 2005;19:573-85.

14 McKay D, Piacentini J, Greisberg S, Graae F, Jaffer M, Miller J, et al. The Children's Yale-Brown Obsessive-Compulsive Scale: item structure in an outpatient setting. Psychol Assess. 2003;15:578-81.

15 Storch EA, Murphy TK, Geffken GR, Bagner DM, Soto O, Sajid $M$, et al. Factor analytic study of the Children's Yale-Brown Obsessive-Compulsive Scale. J Clin Child Adolesc Psychol. 2005;34: 312-9.

16 Storch EA, Rasmussen SA, Price LH, Larson MJ, Murphy TK, Goodman WK. Development and psychometric evaluation of the Yale-Brown Obsessive-Compulsive Scale--Second Edition. Psychol Assess. 2010;22:223-32

17 Wu MS, McGuire JF, Horng B, Storch EA. Further psychometric properties of the Yale-Brown Obsessive Compulsive Scale--Second Edition. Compr Psychiatry. 2016;66:96-103.
18 Hiranyatheb T, Saipanish R, Lotrakul M, Prasertchai R, Ketkaew W, Jullagate $S$, et al. Reliability and validity of the Thai self-report version of the Yale-Brown Obsessive-Compulsive Scale-Second Edition. Neuropsychiatr Dis Treat. 2015;11:2817-24.

19 Melli G, Avallone E, Moulding R, Pinto A, Micheli E, Carraresi C. Validation of the Italian version of the Yale-Brown Obsessive Compulsive Scale--Second Edition (Y-BOCS-II) in a clinical sample. Compr Psychiatry. 2015;60:86-92.

20 Guo X, Meng Z, Huang G, Fan J, Zhou W, Ling W, et al. Metaanalysis of the prevalence of anxiety disorders in mainland China from 2000 to 2015. Sci Rep. 2016;6:28033.

21 National Institute of Mental Health. Clinical global impressions. In: Guy W, editor. ECDEU assessment manual of psychopharmacology. Rockville: United States Department of Health, Education, and Welfare; 1976. p. 218-22.

22 Geller DA, Hoog SL, Heiligenstein JH, Ricardi RK, Tamura R, Kluszynski S, et al. Fluoxetine treatment for obsessive-compulsive disorder in children and adolescents: a placebo-controlled clinical trial. J Am Acad Child Adolesc Psychiatry. 2001;40:773-9.

23 March JS, Biederman J, Wolkow R, Safferman A, Mardekian J, Cook $\mathrm{EH}$, et al. Sertraline in children and adolescents with obsessivecompulsive disorder: a multicenter randomized controlled trial. JAMA. 1998;280:1752-6.

24 Hollander E, Koran LM, Goodman WK, Greist JH, Ninan PT, Yang H et al. A double-blind, placebo-controlled study of the efficacy and safety of controlled-release fluvoxamine in patients with obsessivecompulsive disorder. J Clin Psychiatry. 2003;64:640-7.

25 Murphy DL, Pickar D, Alterman IS. Methods for the quantitative assessment of depressive and manic behavior. In: Burdock El, Sudilovsku A, Gershon S, editors. The behaviour of psychiatric patients: quantitative techniques for evaluation. New York: Marcel Dekker; 1982. p. 355-92.

26 Foa EB, Huppert JD, Leiberg S, Langner R, Kichic R, Hajcak G, et al The obsessive-compulsive inventory: development and validation of a short version. Psychol Assess. 2002;14:485-96.

27 Abramowitz JS, Deacon BJ. Psychometric properties and construct validity of the Obsessive-Compulsive Inventory--Revised: replication and extension with a clinical sample. J Anxiety Disord. 2006;20: 1016-35.

28 Huppert JD, Walther MR, Hajcak G, Yadin E, Foa EB, Simpson HB, et al. The OCI-R: validation of the subscales in a clinical sample. J Anxiety Disord. 2007;21:394-406.

29 Grabill K, Merlo L, Duke D, Harford KL, Keeley ML, Geffken GR, et al. Assessment of obsessive-compulsive disorder: a review. J Anxiety Disord. 2008;22:1-17.

30 Lovibond $\mathrm{SH}$, Lovibond PF. Manual for the depression anxiety \& stress scales. 2nd Ed. Sydney: Psychology Foundation; 1995.

31 Amir N, Foa EB, Coles ME. Factor structure of the Yale-Brown Obsessive Compulsive Scale. Psychol Assess. 1997;9:312-6.

32 Bentler PM, Bonett DG. Significance tests and goodness-of-fit in the analysis of covariance structures. Psychol Bull. 1980;88:588-606.

33 Browne MW, Cudek R. Alternative ways of assessing model fit. In: Bollen KA, Long JS. Testing structural equation models. Newbury Park: Sage; 1993. p. 136-62.

34 Tabachnick BG, Fidell LS. Using multivariate statistics (4th ed.) Needham: Allyn \& Bacon; 2001.

35 Ruscio AM, Stein DJ, Chiu WT, Kessler RC. The epidemiology of obsessive-compulsive disorder in the national comorbidity survey replication. Mol Psychiatry. 2010;15:53-63. 